\title{
Power Quality Improvement of Grid Connected Photovoltaic Solar Systems using 3 level Inverter
}

\author{
Manisha Malik, PR Sharma
}

Abstract: This paper demonstrate simulation modeling of gridtied SPV systems with a 3 level inverter for power quality improvement using SVPWM. To extract maximum power MPPT is used. Three level inverters are used in high power and high voltage application with reduced harmonic contents. The grid tied PV system using three levels inverter has less harmonic contents as comparison of the conventional system or without a three level inverter. The simulation study reveals that the system with three-level inverter using the SVPWM technique generates less THD compared to the conventional system.

Keywords: solar system, three-level inverter, SVPWM, THD.

\begin{tabular}{|l|}
\hline ABBREVIATIONS \\
SVPWM- space vector pulse width \\
modulation \\
THD - total harmonic distortion \\
SPV - solar photovoltaic \\
PQ - power quality \\
EBC - electronic boost converter \\
MPPT - maximum power point tracking \\
\end{tabular}

\section{INTRODUCTION}

The increasing demand for electricity day by day has acquired new schemes for maximizing production of electricity, that include the efficient consumption of renewable power sources such as SPV, tidal energy, wind energy system, hydel energy, etc. Some of the contemporary loads have an unpredictable nature and very complex like industrial loads. To improve voltage profile and reduce transmission losses the reactive power demand by distributed generation endorsement is required [1], [2].

In renewable energy sources, the solar PV sources offers encouraging alternative to overcoming the energy problem and generate green energy. Now a day the grid-connected solar photovoltaic system is most commonly used since they can transfer the additional solar energy to the grid \& secure supply to the local load[3], [4]. The grid-connected distributed generation system has complex controllability \& low efficiency. The problem of grid instability, voltage fluctuation, transient instability, harmonics, and frequency deviation occurs if a system is not properly controlled [5], [6]. In a distributed generation system most of the loads are balanced/unbalanced, linear/ nonlinear or combination of both.
At the utility end, an unbalanced load causes unbalanced voltage. Recently, for UPS (uninterrupted power supplies) \& adjustable speed drive power converter is used. They absorbed harmonic current and increasing demand for power [7].Due to this power quality problem creates in the system network [8]. The integration of natural power sources to the grid intensifies growing concern for power quality. The appropriate corrective solution for power quality problems needs a highly integrated computational technique [9]. This paper introduces simulation and exploration of gridconnected solar PV systems using multilevel inverter for harmonics elimination. A three-level inverter is implemented by using a SVPWM method. This software implementation is accomplished by means of the MATLAB/Simulink software. The SVPWM provides superior harmonic quality in three levels inverter.

\section{GRID CONNECTED SOLAR PHOTOVOLTIC SYSTEM}

A simulation model is developed for power quality scrutiny of the solar PV scheme. In a grid-tied Photovoltaic solar system MPPT technique is designed that is hinge on radial basis function network. In the PV energy system the key objective is to extract the utmost power from the erratic and intermittent type renewable power sources. The solar PV system is constructed by considering the $560-\mathrm{W}$ photovoltaic solar system having the conventional electronic boost converter. The power advanced from the renewable sources leads to erratic voltage owing to high penetration of these sources in nature. Therefore, to smoothen out these variations power electronic converters are used. To track the utmost accessible power from the solar energy system it requires a maximum power point tracking control techniques. The EBC is able to convert low solar voltage to the essential value of voltage by means of changing the duty cycle at the greater switching frequency rate in the system [22]. The schematic diagram of grid-tied solar power system is presented in Fig.1.

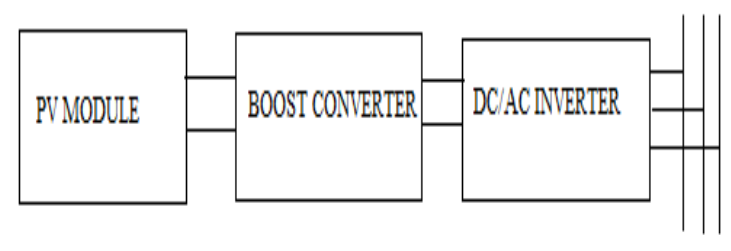

GRD

Revised Manuscript Received on November 06, 2019.

Manisha Malik PhD Scholar, J.C Bose University of Science \& Technology, YMCA Faridabad. manishamaalik@gmail.com

P.R. Sharma, Professor, J.C. Bose University of Science and Technology, YMCA Faridabad. prsharma1966@gmail.com 


\section{THREE-INVERTER USING SVPWM}

Three-level inverter is become more attractive due to numerous features such as improved THD, increase power rating, low switching losses \& low electromagnetic emission. The multilevel inverter delivers output voltage at lessened switching frequency with reduced harmonic distortion. Its operation also required low blocking voltages switches [10]-[13]. A 3 level inverter system has been extensively used in the middle and high voltage excessive capacity AC speed regulating fields, seeing that its output has low harmonic contents, greater power quality, lesser switching losses, improved electromagnetic compatibility and other advantages. In spite of this, it still suffers from some crucial problems, comprising the voltage control at neutral point in the over modulation region, simplification of the three-level algorithm and stability of the systems at higher voltage [14]-[17]. Because of the above problems, Different PWM - techniques have the main target is abbreviating the THD of the system current. As we enhance the switching frequency, lower harmonics are going to reduced, which gives to a lower Total Harmonic Distortion, to calculate a voltage output waveform with the required frequency and RMS values and a sinusoidal waveform resemblance. SVPWM generates the gate drive signal for each Pulse width modulation cycle. The inverter is consider as one single unit and can combine various switching states in which the number of switching states are depends on levels of the inverter. SVPWM technique has become the popular PWM approach for three-level inverter because of its reduced harmonic distortion and increased DC bus utilization. The SVPWM technique provides unique switching time calculations for each of the states. This algorithm can easily be changed lower to higher levels and services for all kinds of multilevel inverters (capacitor clamped, cascaded, diode clamped) [18]-[21]. In this article, we study three-level inverter topology in a PV solar system using space vector pulse width modulation algorithm. The schematic figure of grid-tied SPV systems with 3 level inverter using SVPWM technique is presented in Fig. 2.

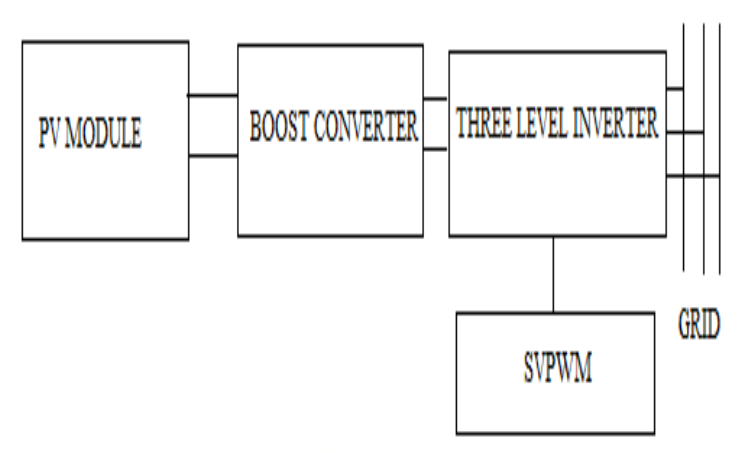

\section{Fig. 2. Schematic diggram of gind connected PV system with huree level inverter using SVPWM}

A 3-stage PWM inverter adjusts DC power of the network into astonishing air conditioning power which is built up here. Simulink model of SVPWM is seemed in Fig. 3. The simple method for delivering the SVPWM signal is by looking at a sinusoidal wave of having low power reference with a high reappearance wave of triangular shape.
A SVPWM inverter produces better waveforms at no genuine increment in expense.

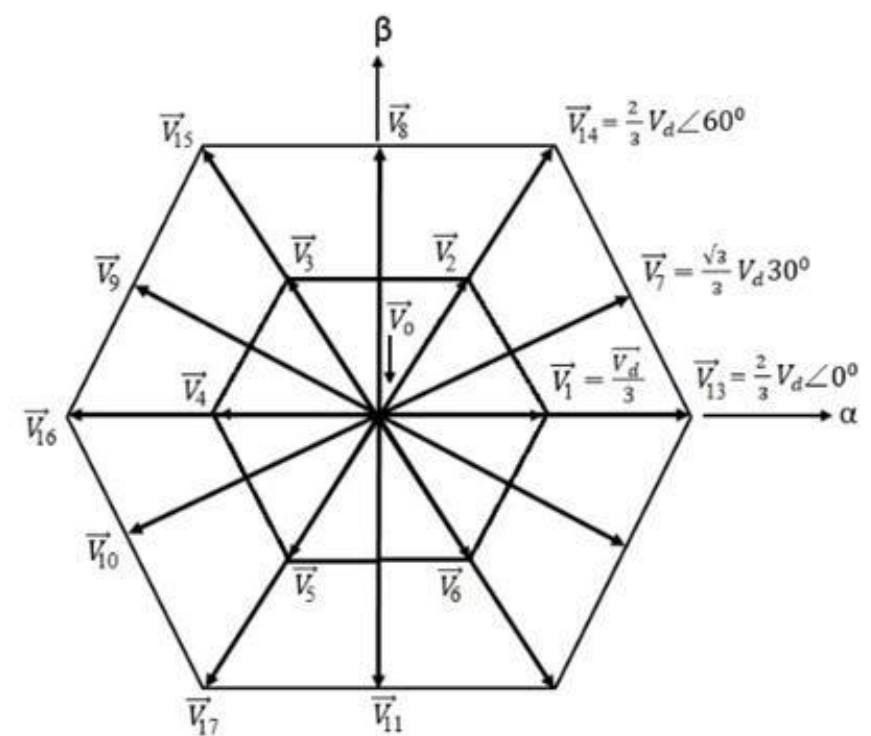

Fig.3. Three phase sinusoidal system with rotating equivalent space vector

The RMS ac output voltage is

$V a c=V s \sqrt{p \delta / \pi}$

Where $\mathrm{p}=$ number of pulses

$\delta=$ pulse width.

\section{PROPOSED SYSTEM}

A SPV system is described by using solar energy sources with the EBC systems. The solar system is fed to the conventional EBC and the DC link bus capacitor is used to stabilize the DC link voltage of the grid-connected inverter. MPPT method is mandatory for SPV system to harvest extremity probable power from the solar irradiation environments. From all the presented MPPT techniques in the article, the best suitable tracking procedure are Hill climbing, Incremental conduction and P\&O approaches, due to easy to implement and its simple structure[22], [23]. These techniques are having shortcoming of fixed step size. In this solar PV system to track maximum power MPPT controller is considered that is found on radial basis function network. A 3 level neutral point clamped electronic inverter is used in the system. It contains twelve switching devices and also provided with two series connected capacitors which are charged with VDC. The DC-voltage neutral point is a point between the capacitor. Each phase leg consists of two clamping diodes and 4 series-connected switching devices (IGBT's). They used to clamp the six middle electronic switches potential to the DC-link point at zero. The particular combinations of the twelve switches deliver the 3 level output voltage. The Simulink model of the gridtied SPV systems with 3 level inverter using SVPWM method is presents in Fig.4. 


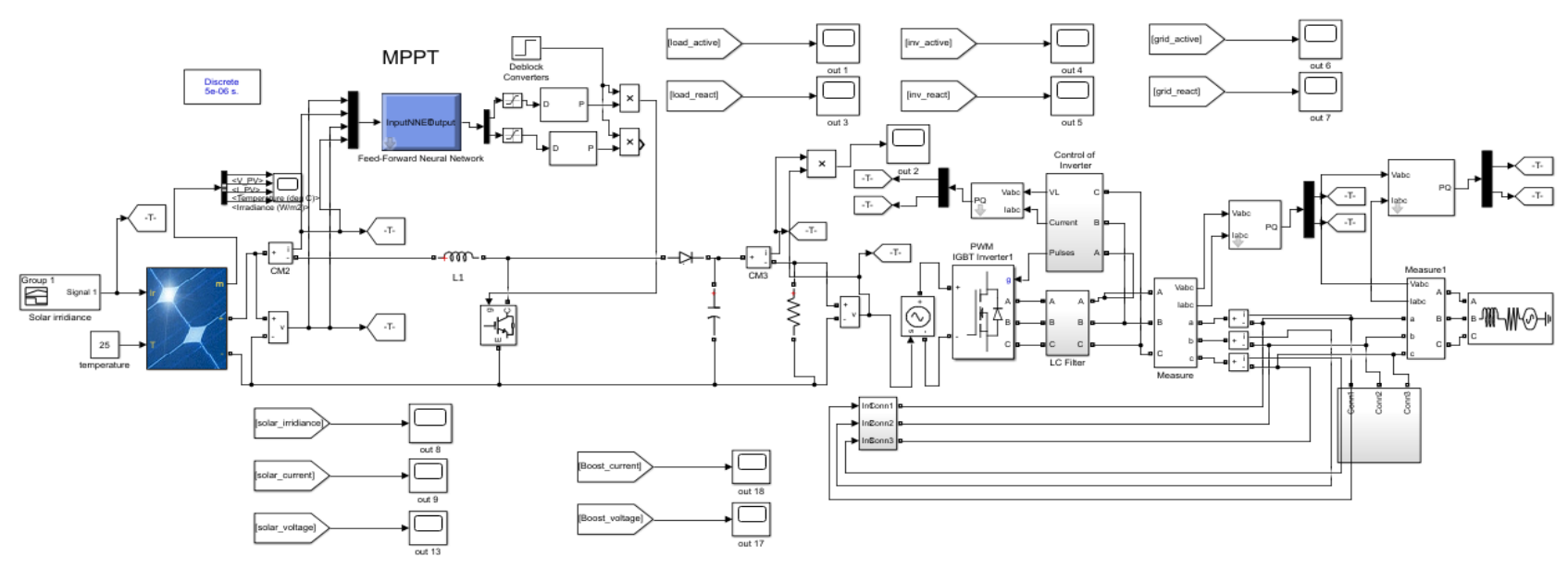

Fig.3. simulation model of grid tied PV solar system with 3 level Iinverter

\section{SIMULATION AND RESULT ANALYSIS}

To study the suitability of suggested grid tied solar PV system, firstly conventional system or without using threelevel inverter is premeditated and simulated in the MATLAB/Simulink systems, as displayed in Fig.4. Secondly grid tied system with 3 level inverter using SVPWM is considered.

The simulation result for THD of load voltage and load current both grids tied solar PV systems without three- level inverter (conventional system) and grid connected photovoltaic solar system by using 3 levels inverter are given in Fig. 5 to Fig. 8. From simulation result we conclude that total harmonic distortion is lesser in grid tied PV solar system using three-level inverter as comparison of conventional system shown in Table 1 .

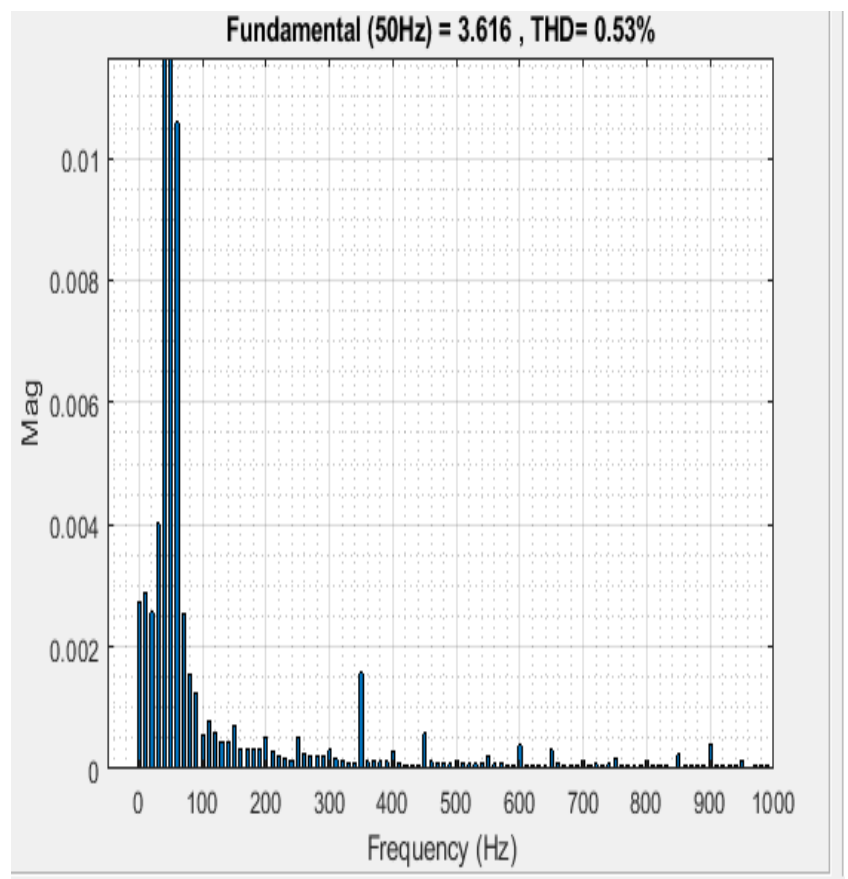

Fig.5. THD of load current in conventional system

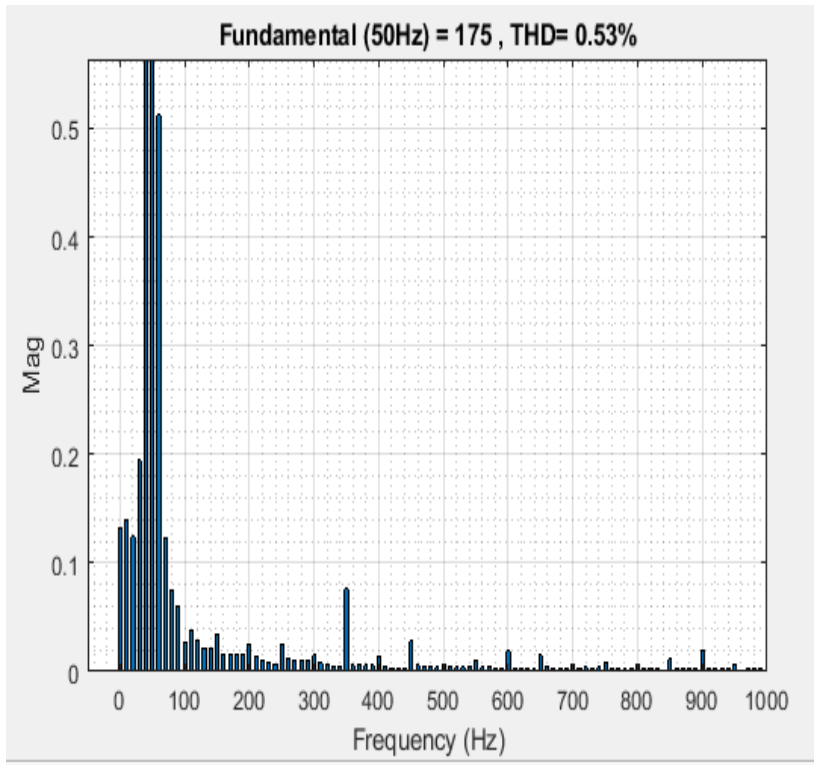

Fig.6. THD of load voltage in conventional system

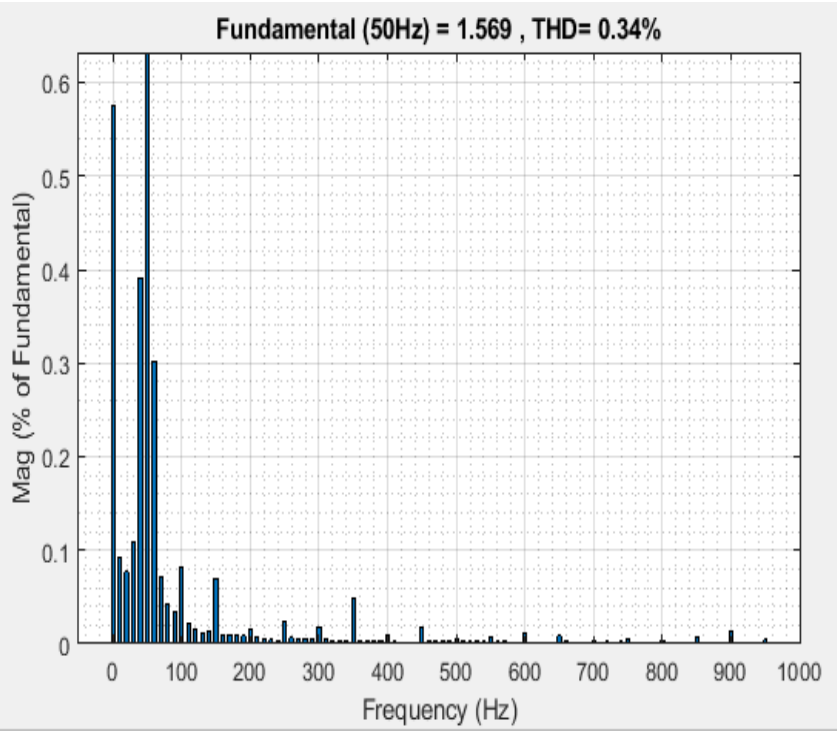

Fig.7. THD of load current in system using three-level inverter 


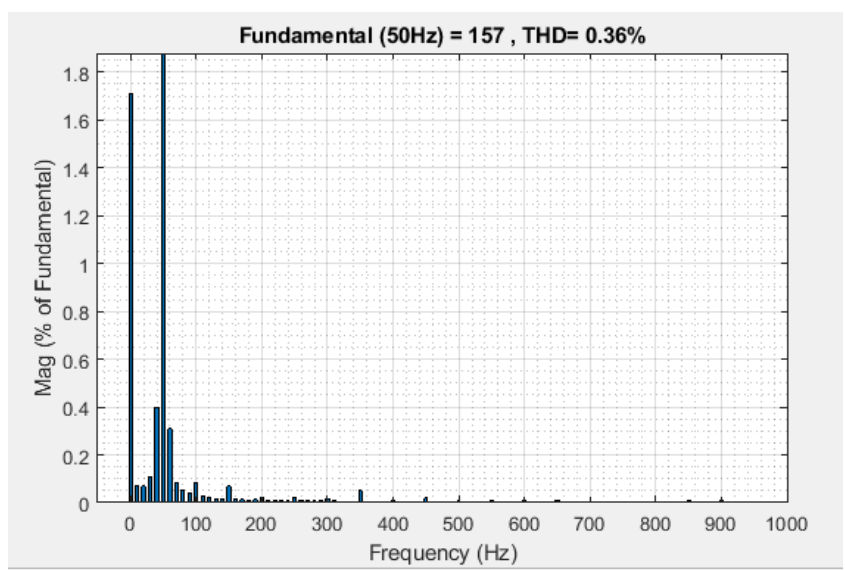
inverter

Fig.8. THD of load voltage in system using 3 levels

table 1.Comparison of grid connected SPV system without 3 level inverter \& with 3 level inverter

\begin{tabular}{|l|l|l|}
\hline Type & $\begin{array}{l}\text { Grid tied SPV } \\
\text { system without } \\
\text { level inverter } \\
\text { (THD) }\end{array}$ & $\begin{array}{l}\text { Grid tied SPV system } \\
\text { with 3 level inverter } \\
\text { (THD) }\end{array}$ \\
\hline Load current & $0.53 \%$ & $0.34 \%$ \\
\hline Load voltage & $0.53 \%$ & $0.36 \%$ \\
\hline
\end{tabular}

\section{CONCLUSION}

The article presents the PQ improvement of a grid tied PV solar systems with a 3 level inverter by using a space vector pulse modulation method. The harmonic presents in the planned system are efficiently diminished using a three-level inverter. Comparison by the conventional systems, the gridtied solar system with a three-level inverter is lesser THD. The paper aimed to help the researcher to upgrade the power quality of the grid-connected systems using multilevel inverter ( 5 levels, 7 levels, etc.) for reduced THD in the system.

\section{REFERENCES}

1. R. G. Wandhare and V. Agarwal, "Reactive Power Capacity Enhancement of a PV-grid system to increase PV penetration level," Int. J. Latest Trends Eng. Technol., vol. 8, no. 1, pp. 1-10, 2016.

2. K. Jain, A. Bhargava, and B. Mewara, "Power quality enhancement using unified power flow controller in standalone grid-connected solar PV system," Proc. Int. Conf. Inven. Res. Comput. Appl. ICIRCA 2018, no. Icirca, pp. 709-713, 2018.

3. C. :Bouzi. Khomsi M.:Jelassi, K., "Power Quality Improvement in a Three-Phase Grid-Tied Photovoltaic System Supplying Unbalanced and Nonlinear Loads," Int. J. Renew. Energy Res., vol. 8, no. 2, pp. 1165-1177, 2018.

4. Q.N.Trinh and H.H. Lee, “An Enhanced Grid Current Compensator for Grid-Connected Distributed Generation Under Nonlinear Loads and Grid Voltage Distortions," IEEE Trans. Ind. Electron., vol. 61, no. 12 , pp. $6528-6537,2014$.

5. H. M. Ali Zeeshan, F. Nisar, and A. Hassan, "A review of distributed control techniques for power quality improvement sin micro-grids," IOP Conf. Ser. Mater. Sci. Eng., vol. 199, no. 1, 2017.

6. M Khatri and A Kumar," experimental investigation of harmonic in a grid tied solar photovoltaic system," vol. 7. no. 2, 2017.

7. V. Rani, O. P. Mahela, and H. Doraya, "Power Quality Improvement in the Distribution Network with Solar Energy Penetration using Distribution Static Compensator," 2018 Int. Conf. Comput. Power Commun. Technol. GUCON 2018, pp. 148-154, 2019.

8. A G Shaik and O P Mahela, "power quality assessment and event detection in hybrid power system," electrical power system Res., vol.161, pp.26-44, 2018.

9. O. P. Mahela, K. Dev Kansal, and S. Agarwal, "Detection of power quality disturbances in utility grid with solar photovoltaic energy penetration," India Int. Conf. Power Electron. IICPE, vol. 2018Decem, pp. 1-5, 2019.
10. H. A. Toliyat, Analysis of Electric Machinery and Drive Systems [Book Review], vol. 22, no. 9. 2005.

11. H. Akagi and T. Hatada, "Voltage Balancing Control for a ThreeLevel Diode-Clamped Converter in a Medium-Voltage Transformerless Hybrid Active Filter," IEEE Trans. Power Electron., vol. 24, no. 3, pp. 571-579, 2009.

12. M. Tamasas, M. Saleh, M. Shaker, and A. Hammoda, "Evaluation of Modulation Techniques for 5-level Inverter Based on Multicarrier Level Shift PWM," Proc. Mediterr. Electrotech. Conf. - MELECON, vol. 2, no. April, pp. 17-23, 2014.

13. G. Tan, Q. Deng, and Z. Liu, "An Optimized SVPWM Strategy for Five-Level Active NPC (5L-ANPC) Converter," IEEE Trans. Power Electron., vol. 29, no. 1, pp. 386-395, 2014.

14. S. V Patel and B. R. Nanecha, "3 Level Svpwm Solar Inverter Using Dsp Controller," pp. 3-6, 2016.

15. A. Tuluhong, W. Wang, Y. Li, and L. Xu, "A novel hybrid T-type three-level inverter based on SVPWM for PV application," J. Electr. Comput. Eng., vol. 2018, pp. 1-12, 2018.

16. P. M. Meshram, D. Hanote, and M. M. Renge, "A Simplified SpaceVector PWM for Three Level Inverters Applied to Passive and Motor Load," 2009 4th IEEE Conf. Ind. Electron. Appl. ICIEA 2009, pp. 3388-3393, 2009.

17. J. Dario Betanzos Ramirez, J. Jose Rodríguez Rivas, and E. Peralta Sanchez, "Space Vector Pulse Width Modulation for Three-Level NPC-VSI," IEEE Lat. Am. Trans., vol. 11, no. 2, pp. 759-767, 2013.

18. Z. Gao, T. Chen, and C. Zhang, "Control of an Active Bus Voltage Limiter with Modified Space Vector Pulse Width Modulation Strategies in Regenerative Applications," Control Eng. Pract., vol. 83, no. November 2018, pp. 176-187, 2019.

19. T. E. Shults, O. Husev, F. Blaabjerg, C. Roncero-Clemente, E. Romero-Cadaval, and D. Vinnikov, "Novel space vector pulse width modulation strategies for single-phase three-level NPC impedancesource inverters," IEEE Trans. Power Electron., vol. 34, no. 5, pp. 4820-4830, 2019.

20. R. Attia, "Space Vector Pulse Width Modulation," 2018 Int. Conf. Appl. Smart Syst., no. November, pp. 223-240, 2010.

21. K. Lavanya and V. Rangavalli, "A novel technique for simulation \& analysis Of SVPWM two \& three level inverters," Int. J. Eng. Res Appl., vol. 3, no. 5, pp. 455-460, 2013.

22. K. Kumar, R. N. Babu, and K. R. Prabhu, "Design and Analysis of RBFN-Based Single MPPT Controller for Hybrid Solar and Wind Energy System,” IEEE Access, vol. 5, pp. 15308-15317, 2017.

23. S. Saravanan and N. Ramesh Babu, "RBFN Based MPPT Algorithm for PV System with High Step Up Converter," Energy Convers. Manag., vol. 122, pp. 239-251, 2016.

\section{AUTHORS PROFILE}

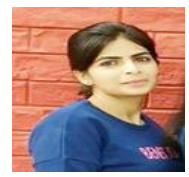

Manisha Malik $\mathrm{PhD}$ Scholar at J.C Bose University of Science \& Technology, YMCA Faridabad her research interest include power system stability, Power quality related issues and renewable energy resources.

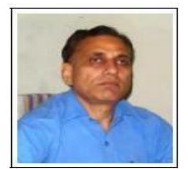

P.R. Sharma (1966-) India, Professor at J.C. Bose University of Science and Technology, YMCA Faridabad, guided many $\mathrm{PhD}$ scholars, his research direction include power system stability, Optimal location and coordination of FACTS devices Power quality related issues and renewable energy resources. 